Chang, S. ; Waite, T.D. ; Ong, P.E.A. ; Schäfer, A.I. ; Fane, A.G. (2004)

Assessment of Trace Estrogenic Contaminants Removal by Coagulant Addition, Powdered Activated Carbon Adsorption and Powdered Activated Carbon/Microfiltration Processes,

ASCE Journal of Environmental Engineering, 130, 7, 736-742.

\section{Assessment of Trace Estrogenic Contaminants Removal by Coagulant Addition, Powdered Activated Carbon Adsorption and Powdered Activated Carbon/Microfiltration Processes}

Sheng Chang ${ }^{1}$; T. David Waite ${ }^{2}$; Peter E. A. Ong ${ }^{3}$; Andrea I. Schäfer ${ }^{4}$ and Anthony G. Fane ${ }^{5}$

${ }^{1}$ Research Associate, Centre for Water and Waste Technology, School of Civil and Environmental Engineering, The University of New South Wales, Sydney, NSW 2052, Australia.

${ }^{2}$ Professor, Centre for Water and Waste Technology, School of Civil and Environmental Engineering, The University of New South Wales, Sydney, NSW 2052, Australia, (corresponding author). E-mail: D.Waite@unsw.edu.au, Tel: 61-2-9385 5060,Fax: 61-2-9385 6139.

${ }^{3}$ Undergradulate student, School of Civil and Environmental Engineering, The University of New South Wales, Sydney, NSW 2052, Australia

${ }^{4}$ Lecturer, Centre for Water and Waste Technology, School of Civil and Environmental Engineering, The University of New South Wales, Sydney, NSW 2052, Australia.

${ }^{5}$ Professor, UNESCO Centre for Membrane Science and Technology, School of Chemical Engineering and Industrial Chemistry, The University of New South Wales, Sydney, NSW 2052, Australia,

Abstract: Increasing attention is being paid to health and environmental risk as a result of the presence of trace steroid estrogens in the effluent discharged from municipal sewage treatment plants. This paper focuses on assessment of removal of these trace compounds using ${ }^{3} \mathrm{H}$-labelled estrone as the model compound. Jar tests over a range of ferric chloride dosage and $\mathrm{pH}$ conditions showed that coagulation was ineffective in removal of estrone from secondary effluent. The experiments showed that the combination of PAC and microfiltration could be effective for removal of trace estrone from water. The rate and extent of estrone removal by PAC are functions of PAC dosage and retention time of $\mathrm{PAC}$ in the system. Mathematical analysis of the results using a homogeneus surfce diffusion model (HSMD) indicates that the adsorption of estrone on PAC can homogeneous su be limited by film diffusion and internal surface diffusion. The surface and film mass transfer coefficients were determined to be $9.72 \times 10^{-10} \mathrm{~cm}^{2} / \mathrm{min}$ and $1.963 \mathrm{~cm} / \mathrm{min}$, respectively, under the conditions used.

Keywords: Estrogenic compound; Adsorption; Coagulation; Hybrid membrane process.

\section{Introduction}

Endocrine disrupting and pharmaceutically active compounds which are excreted by humans and enter the environment via effluent discharge from municipal sewage treatment plants (STPs) may have significant impacts on both biota exposed in the receiving environment and human health (Ternes 1999; Hirsch 1999; Körner 2000). Although field data suggests that modern activated (Ternes 1999; Hirsch 1999; Körner 2000). Although field data suggests that modern activated
sludge treatment processes could consistently remove most of the synthetic and natural hormones sludge treatment processes could consistently remove most of the synthetic and natural hormones
that enter the works (Johnson and Sumpter 2001), steroid estrogens such as estrone and estradiol still occur at significant concentrations in sewage effluent (Johnson and Sumpter 2001). These trace compounds, usually present in the range of 1 to $30 \mathrm{ng} / \mathrm{L}$, could exert significant effects on biota exposed in the receiving environment (Sumpter and Jobling 1995). One of the possible solutions to enhancing removal of endocrine compounds from secondary
effluent is to combine low-pressure membrane processes such as UF or MF with other physicochemical processes in so-called hybrid membrane processes. In such systems, MF or UF membranes can be a positive barrier for various particulates including clays, metal oxides, algae, bacteria, and parasites such as Cryptosporidium and Giardia, while adsorption to added particulates or hydrolyable coagulants could be effective for removal of dissolved organics. The widely used physicochemical processes in water treatment include activated carbon adsorption and coagulation. Adsorption to hydrolysable coagulants is often very effective in removing acidic and basic components of the dissolved organic matter in natural waters provided $\mathrm{pH}$ conditions and dosage are properly controlled (Dennett et al. 1996). Randtke and McCarty (1979) assessed the potential of (a) of demonstrated that activated carbon adsorption is generally the most proficient in removal of soluble organic matter. Morris and Weber $(1964 ; 1969)$ presented a considerable amount of data on the adsorption of phenol, sodium salts of sulfonated organics, and pesticides. The kinetics of adsorption of organics on activated carbon have also been extensively studied by a number of investigators (Weber and Chakravorty 1974; Traegner and Suidan 1989; Roy et al. 1993; Najm 1996; Knappe et al. 1998). Research has also been undertaken showing that the combination of MF/UF with coagulation or carbon adsorption could be very effective for organic removal in tertiary wastewater or drinking water treatment. Lee et al. studied removal of phenol by adsorption on powdered activated carbon in a continuous flow stirred cell membrane system and reported that the kinetic activated carbon in ce well described by a sur Campos et al developed mathematic models based on HSDM for PAC-membrane filtration processes with different process arrangements and verified that these models can be used to predict trace organic removal by the combined membrane PAC systems (Campos et al. 1997; 2000a,b). Best et al. reported that a single tank coagulation-submerged ultrafiltration processes was effective for colour and TOC removal from natural water (Best et al. 1999). Pirbazari et al (1992) reported that high organic removal from water contaminated with natural and synthetic organics can be achieved by combined MF-PAC processes. Similar results with submerged PAC-MF system have also been reported by other researchers (Lebeau et al. 1998; Suzuki et al. 1998).

In this paper, the further removal of trace steroid estrogens by coagulation, PAC adsorption, and PAC-microfiltration processes has been investigated with different background solutions spiked by ${ }^{3} \mathrm{H}$-labelled estrone through jar test, flask adsorption, and stirred cell filtration studies, respectively. The effects of dosage of ferric chloride and $\mathrm{pH}$ on estrone removal, the PAC adsorption isotherm relationship and effect of competitive adsorption, as well as removal rate of estrone by the combined PAC-membrane system have been investigated. In addition, the homogeneous surface diffusion model (HSDM) has been used to assess the mechanisms of mass transfer of estrone adsorption to PAC.

\section{Experimental materials and methods}

Adsorption of estrone to hydrolysable coagulants was investigated through use of a conventional jar-test apparatus. Regular grade ferric chloride $\left(\mathrm{FeCl}_{3} \cdot 6 \mathrm{H}_{2} \mathrm{O}\right)$ was applied at various dosages $(5-50$ $\mathrm{mg} / \mathrm{L}$ ) and $\mathrm{pH}$ conditions (5-11.4) into four beakers containing $100 \mathrm{~mL}$ secondary effluent spiked with estrone (at about $15 \mathrm{ng} / \mathrm{L}$ ). The coagulation protocol involved rapid mixing at $100 \mathrm{rpm}$ for 3 minutes, followed by slow mixing at $30 \mathrm{rpm}$ for 30 minutes. Then, after settling for 60 minutes, the samples were taken from the supernatant. Some of the samples were further treated by filtration different methods of sample treatment.

Flask adsorption experiments were performed to assess the removal capacity of powdered activated carbon for estrone. In these experiments, $50 \mathrm{~mL}$ background solution in the flasks was spiked to an 
Chang, S. ; Waite, T.D. ; Ong, P.E.A. ; Schäfer, A.I. ; Fane, A.G. (2004)

Assessment of Trace Estrogenic Contaminants Removal by Coagulant Addition, Powdered Activated Carbon Adsorption and Powdered Activated Carbon/Microfiltration Processes,

ASCE Journal of Environmental Engineering, 130, 7, 736-742.

estrone concentration of $100 \mathrm{ng} / \mathrm{L}$ and different amounts of PAC $(0.5-50 \mathrm{mg} / \mathrm{L})$ were added to the flasks. The adsorption experiments were conducted in an incubator (Bioline, Edwards Instrument Company Australia) under conditions of $250 \mathrm{rpm}$ mixing speed and $25{ }^{\circ} \mathrm{C}$ for 48 hours enabling equilibrium to be reached. The powdered activated carbon (Norit SAM 52) was provided by Swift, Melbourne. The median particle size $\left(\mathrm{D}_{50}\right)$ of the PAC is $20 \mu \mathrm{m}$ and has a total surface area (BET) of $72.5 \mathrm{~m}^{2} / \mathrm{g}$ and density $450 \mathrm{~kg} / \mathrm{m}^{3}$.

The PAC-MF filtration system used in this study is shown in Figure 1. The system consists of a stirred cell, a magnetic stirrer (Amicon), suction pump, pressure transducer, and computer data collection system. The filtration has been carried out in constant flux mode with the permeate drawn through the membrane by the peristaltic pump and recirculated to the open stirred cell. The cell has an effective volume of $200 \mathrm{~mL}$ and a certain amount of PAC was directly added into the cell during the experiments. The suction pressure was measured by a pressure transducer. The samples were taken either from the permeate side or both the permeate and feed sides at a certain time intervals a required. The membrane used in the filtration experiments was a hydrophilic GVWP membrase (Millipore) which has a nominal pore size of $0.22 \mu \mathrm{m}$. A new membrane was used for each experiment.

Background solutions of either $1 \mathrm{mM} \mathrm{NaHCO}$ and $20 \mathrm{mM} \mathrm{NaCl}$ buffer (which provided buffering to about $\mathrm{pH}$ 8) or secondary effluent were used. The effluent (TOC $13.2 \mathrm{mg} / \mathrm{L}, \mathrm{pH} 7.2$ to 7.5 ) was taken from St Marys Sewage Treatment Plant, NSW, Australia. Test solutions were prepared by dissolving a certain amount of ${ }^{3} \mathrm{H}$-labelled estrone in the background solutions. The radiolabelled estrone was purchased from Sigma Aldrich (Saint Louis, Missouri, USA). A Packard Instruments scintillation counter which has a detection limit of approximtely $0.1 \mathrm{ng} / \mathrm{L}$ was used for analysis the radiolabelled compounds. A TOC-5000A (Shimadzu) total organic carbon analyser was used to analyse TOC in the solutions tested.

\section{Results and discussion}

Estrone removal by adsorption to hydrolysable coagulant

Adsorption to hydrolysable metal salts is effective for removal of dissolved organic matter (DOM) from water. The metal ions which exist in aqueous phase as aquometal complexes can be hydrolysed to positive or negative hydroxocomplexes depending on $\mathrm{pH}$ conditions. These hydrolysis products destabilize colloids in two ways: either by adsorption and charge neutralization, or by enmeshment in a sweep floc (Stumm and O'Melia 1968). In this study the effect of coagulation on estrone removal was assessed through jar test experiments using $\mathrm{FeCl}_{3}$ as coagulant coagulation on estrone removal was assessed through jar test experiments using $\mathrm{FeCl}_{3}$ as coagulan and secondary effluent as a background solution that was spiked with estrone to a concentration of
$15 \mathrm{ng} / \mathrm{L}$. Figure 2 a shows the estrone concentration before and after coagulation with non-adjusted initial $\mathrm{pH}(\mathrm{pH}=7.5)$ and different dosages of $\mathrm{FeCl}_{3}$. The samples after coagulation were taken from the supernate after settling the solution for one hour. Although a significant amount of floc formed during all the experiments and about $28 \%$ and $50 \%$ TOC removal was achieved for ferric chloride doses of 20 and $50 \mathrm{mg} / \mathrm{L}$ respectively, only about 23 to $5 \%$ of the estrone was removed by adsorption to the precipitated congulant. Figure $2 \mathrm{~b}$ shows that the estrone concentration before and after coagulation with different $\mathrm{pH}$ conditions and a dosage of $30 \mathrm{mg} / \mathrm{L}$. Although the
experiments showed that the removal of TOC could be significantly affected by $\mathrm{pH}$, no obvious experiments showed that the removal of TOC could be significantly affected by $\mathrm{pH}$,
change in estrone removal was observed for coagulation under different $\mathrm{pH}$ conditions.

Figure 3 compares the results obtained with samples treated by coagulation + settling and coagulation + membrane filtration. The membrane used was a PLHK membrane (MWCO, $100 \mathrm{kDa}$, Millipore), which is assumed to only allow passage of dissolved organics. From this figure, it can be seen that the results for these different treatment methods are quite similar, suggesting that the estrone added remains in solution after the addition of hydrolysable metal salts.
The results of these studies show that there are negligible interactions between trace estrone, colloids, and coagulants. This scenario is quite different to those obtained with relatively high estrone concentration $(0.1 \mu \mathrm{g} / \mathrm{mL})$ where a significant interaction between estrone and clay particles was observed (Lai et al. 2000). This suggested that further delimitation of trace estrogenic contaminants could become more difficult due to the decrease potential of interactions with other molecules or colloids in water.

\section{Estrone removal by powder activated carbon}

The ability of activated carbon to remove trace estrone from water was assessed through flask adsorption experiments. Figure 4 shows the final equilibrium estrone concentration achieved during adsorption of estrone from buffer solutions initially spiked to 120,70 and $15 \mathrm{ng} / \mathrm{L}$ estrone after 48 hour adsorption. The final equilibrium concentration decreased with increase in PAC dosage until a limiting final concentration was reached. For an initial estrone concentration of $120 \mathrm{ng} / \mathrm{L}$, a final concentration of $3.8 \mathrm{ng} / \mathrm{L}$ was achieved. When such an equilibrium concentration was reached, increasing PAC dosage did not lead to any further decrease in the final equilibrium concentration. increasing PAC dosage did not lead to any further decrease in the final equilibrium concentration.
For initial concentrations of 70 and $17 \mathrm{ng} / \mathrm{L}$, the final (equilibrium) concentrations achieved were For initial concentrations of 70 and $17 \mathrm{ng} / \mathrm{L}$, the final (equilibrium) concentrations achieved were
about 2.5 and $0.57 \mathrm{ng} /$, respectively. Comparison between the equilibrium concentrations achieved and the corresponding initial concentrations suggested that the maximum removal of estrone for initial concentrations of 120,70 and $17 \mathrm{ng} / \mathrm{L}$ were consistently in the range of 96 to $97 \%$. This suggests that about 3 to $4 \%$ of estrone in the solutions was not removable by PAC. This conclusion was further confirmed by adding fresh PAC into the solutions after 48 hours of adsorption (by which time equilibrium adsorption had been achieved). Figure 5 shows the initial and final estrone No further removal of the residue of estrone was achieved by the second addition of fresh PAC.

The adsorption capacity of PAC can be characterized by the relationship between the concentration of estrone in the solution and that absorbed by PAC at the equilibrium state. Figure 6 shows the extent of adsorption of estrone to PAC over a range of estrone concentrations in both carbonate buffer solution and secondary effluent. The results obtained in carbonate buffer demonstrate show adsorption capacities ranging from about 1.0 to $17 \mathrm{ng} / \mathrm{mg}$ depending upon the concentration of estrone in solution with the results adequately described by a linear adsorption isotherm over the concentration range tested:

$q_{e}=1.093 C e$

The results obtained using secondary effluent suggest that competitive adsorption may be reducing the adsorption capacity of PAC for estrone. For equilibrium dissolved estrone concentrations of 1.3 to $17.4 \mathrm{ng} / \mathrm{L}$, the amount of estrone adsorbed from the effluent to the PAC at the equilibrium was about 0.3 to $5.7 \mathrm{ng} / \mathrm{L}$; significantly lower than that achieved in carbonate buffer solution. Figure 7 shows that the extent of effect of the competitive adsorption in PAC dosage. For adsorption at low PAC dosage, the final solution concentration of estrone is relatively high. A reasonable explanation of these results is that the equilibrium concentration of estrone is controlled by the adsorption site availability. For adsorption at relatively high PAC doses, the final equilibrium partioning behavior is limited by exhaustion of removable estrone in the solution so that the effect of competitive adsorption decreases while at low PAC doses, the estrone must compete for a limited number of surface sites with other dissolved constituents.

\section{Estrone removal by combined MF-PAC system.}

The results presented in section 3.2 imply that the combination of membrane with PAC could be an effective process for trace estrone removal from water. In such a hybrid membrane process, PAC can be completely retained by the membranes and the retention time is independent of other process 
Chang, S. ; Waite, T.D. ; Ong, P.E.A. ; Schäfer, A.I. ; Fane, A.G. (2004)

Assessment of Trace Estrogenic Contaminants Removal by Coagulant Addition, Powdered Activated Carbon Adsorption and Powdered Activated Carbon/Microfiltration Processes,

ASCE Journal of Environmental Engineering, 130, 7, 736-742.

parameters. The efficiency of removal of estrone by combined MF-PAC processes was tested by combining these two processes using a stirred cell system in a batch operation mode (Figure 1). In these experiments the permeate was drawn through the membrane at a flux of $78 \mathrm{~L} / \mathrm{m}^{2} \mathrm{hr}$ and PAC was directly added into the stirred cell. Before adding PAC into the stirred cell the microfiltration membrane used exhibited about $10 \%$ retention to estrone. Since the pore size of the membrane used here is much larger than that of the estrone molecules, the retention of this compound to the membrane coul be attibut to adsorption. A detailed discussion on membrane surfaces is been presented in another paper [Chang et al., 2002].

Figure 8 shows the change in estrone concentration in the permeate after addition of different doses of PAC into the stirred cell containing estrone spiked solution. The results show that when the PAC dosage was lower than $20 \mathrm{mg} / \mathrm{L}$ the removal rate was a strong function of PAC dosage; in othe words, a significantly higher removal of estrone at a certain time could be achieved with higher PAC dosage. Almost no difference in removal rate was observed for adsorption with PAC doses of 20 and $30 \mathrm{mg} / \mathrm{L}$, indicating that the process was controlled by the concentration of estrone in solution rather than adsorption sites required. The results shown in Figure 8 also suggest that me. For PAC concentrations of $20 \mathrm{mg} / \mathrm{L}$ or higher, about $91 \%$ removal was achieved in the first hour and maximum removal (96\%) was reached in three hours. These results demonstrate that PAC dosage and its retention time are important factors in achieving the desired removal efficiency. Figure 9 compares estrone removal by PAC from secondary effluent and buffer solution at different PAC dosages. From the figure it can be seen that lower estrone removal was achieved with the effluent over the period of the tests, suggesting the presence of other organics not only impacted the removal degree but also removal rate.

\section{Adsorption kinetics}

As shown in Figure 10, removal of estrone by PAC adsorption comprises a number of transport steps, including bulk solution transport, external (film) transport, internal (pore) transport, and adsorption. Once the molecules reach the boundary layer around the activated carbon particles through bulk transport, they will diffuse through the stagnant film layer and are assumed to penetrate further into the particle by surface diffusion to the adsorption site. The adsorption rate can be limited by one or more than one transport steps involved. In a mixed system, the transport rate is usually limited by film diffusion and internal surface diffusion. For such systems, the homogeneous surface diffusion model (HSDM) can be used to describe the adsorption process (Weber and Chakravorty 1994 Chakravory 1994; Roy et a 1993; Traegn and suics equations and initial and boundary conditions involved in HSDM theory for closed batch
adsorption.

Roy et al. (1993) developed a simplified solution for the HSDM using the orthogonal collocation techniques (using three orthogonal collocation points) and Laplace transformation, which can reduce the equations in Table 1 into five non-linear algebraic equations. For a linear isotherm relationship, the HSDM solution can be simplified to the following set of equation for cases with and without film diffusion:

For non-film diffusion limitation

$\frac{C_{t}}{C_{0}}=\frac{1}{1+3 K \frac{M}{V} A}$

where

$$
\begin{aligned}
& A=0.333-0.049 \exp \left[-143\left(\frac{4 D_{s}}{d_{p}^{2}}\right)\right]-0.054 \exp \left[-40 t\left(\frac{4 D_{s}}{d_{p}^{2}}\right)\right] \\
& -0.202 \exp \left[-9.87 t\left(\frac{4 D_{s}}{d_{p}^{2}}\right)\right]
\end{aligned}
$$

For surface and film diffusion limitation

$\frac{C_{t}}{C_{0}}=\frac{1}{1+3 K \frac{M}{V} B i \frac{A}{B i+E}}$

where

$E=2.144+0.049 \exp \left[-12.9\left(\frac{4 D_{s}}{d_{p}^{2}}\right)\right]+1.58 \exp \left[-40 t\left(\frac{4 D_{s}}{d_{p}^{2}}\right)\right]$

$+2.01 \exp \left[-9.87 t\left(\frac{4 D_{s}}{d_{p}^{2}}\right)\right]$

$B i=\frac{K_{f} d_{p} C_{0}}{2 D_{s} \rho_{p} q_{0}}$

$\mathrm{Bi}$ is the non-dimensional Biot number and represents the ratio of the rate of transport across the liquid layer to the rate of diffusion within the particle. According to Roy et al (1993), for $\mathrm{Bi}<<1$, film diffusion dominates the mass transfer, while for $\mathrm{Bi}>>100$, internal surface diffusion controls the mass transfer rate. A Biot number between 1 and 100 indicates that the process is limited by both mass transfer mechanisms.

The developed models can be used to determine the film diffusion coefficient $\left(\mathrm{K}_{\mathrm{f}}\right)$ and surface diffusion coefficient $\left(D_{s}\right)$ by minimizing the sum of the squares of the difference between the diffusion coefficient $\left(\mathrm{D}_{\mathrm{s}}\right)$ by minimizing the sum of the squares of the difference between the
corresponding model solutions and experimental data collected from batch adsorption experiments; i.e.

Minimize $\left[f\left(D_{s}, K_{f}\right)\right]=\sum_{i=1}^{m}\left[\left(\frac{C_{t}}{C_{0}}\right)_{\text {measured }}-\left(\frac{C_{t}}{C_{0}}\right)_{H S D M}\right]^{2}$

The hybrid PAC-membrane system tested here can be regarded as a closed PAC batch adsorption system if the effect of adsorption on the membranes is neglected. The diffusion coefficients for estrone adsorption on the PAC particles was assessed using the developed models and least square residues strategy based on the data obtained from five different initial concentrations and differen times. The surface diffusion coefficient was determined to be $1.38 \times 10^{-10} \mathrm{~cm}^{2} / \mathrm{min}$ for the case in which film diffusion limitation was neglected. When considering the uptake process to be limited by both the effect of film and surface diffusion, the surface diffusion coefficient and film mass transfer coefficient was determined to be $9.72 \times 10^{-10} \mathrm{~cm}^{2} / \mathrm{min}$, and $\mathrm{K}_{\mathrm{f}}=1.963 \mathrm{~cm} / \mathrm{min}$, respectively. The simulated and experimental $\mathrm{C}_{\mathrm{t}} / \mathrm{C}_{0}$-t relationships are given in Figures $11 \mathrm{a}, \mathrm{b}$ show that both The simulated and experimental $\mathrm{C}_{\mathrm{t}} / \mathrm{C}_{0}$-t relationships are given in Figures $11 \mathrm{a}, \mathrm{b}$ show that both
models can predict the total tendency of change in solution concentration to a reasonable accuracy, suggesting that internal surface diffusion is the major factor limiting the rate of adsorption of estrone to PAC. Comparing the $\mathrm{C}_{\mathrm{t}} / \mathrm{C}_{0}$-t relationship simulated by the no-film diffusion limitation model (Figure $11 \mathrm{a}$ )with that predicted by the model considering film diffusion (Figure $11 \mathrm{~b}$ ), the former predicted a much sharper concentration decrease in the initial stages of uptake than that observed experimentally. Such a sharp initial decrease in concentration could be mitigated by film transport or even bulk transport. In fact, the calculation shows that the Biot number for estrone adsorption on PAC is about 4, suggesting that the process is limited by both film and surface 
Chang, S. ; Waite, T.D. ; Ong, P.E.A. ; Schäfer, A.I. ; Fane, A.G. (2004)

Assessment of Trace Estrogenic Contaminants Removal by Coagulant Addition, Powdered Activated Carbon Adsorption and Powdered Activated Carbon/Microfiltration Processes,

ASCE Journal of Environmental Engineering, 130, 7, 736-742.

transport mechanisms. Note that since $\mathrm{q}_{0}$ is proportional to $\mathrm{C}_{0}$, the Biot number and thus $\mathrm{C}_{\mathrm{t}} / \mathrm{C}_{0}$ are expected to be independent of $C_{0}$. That $C_{t} / C_{0}$ is independent of the initial estrone concentration used is confirmed in the experimental results shown in Figure 12.

\section{Conclusions}

In this paper, we have examined the removal of trace concentrations of the natural hormone estrone from water by coagulation, PAC adsorption and PAC-microfiltration membrane processes. The results of studies of estrone removal in the presence of hydrolyzing metal salts in secondary effluent show that there are negligible interactions between trace estrone and aquometal ions or their fine colloidal oxyhydroxide products. As a result, it appears that addition of hydrolysable metal salts is ineffective for trace estrone removal from secondary effluent. In comparison, the results of studies with powdered activated carbon demonstrated that trace estrone can be effectively removed from with aqueous phaction of PAC C. estrone by PAC using HSMD models suggests that the adsorption process is limited by both film diffusion and internal surface diffusion. The surface and film diffusion coefficients were determined to be $9.72 \times 10^{-10} \mathrm{~cm}^{2} / \mathrm{min}$ and $1.963 \mathrm{~cm} / \mathrm{min}$, respectively, for the system examined.

\section{Symbols}

$\mathrm{B}_{\mathrm{i}}=$ Biot number

$\mathrm{C}_{\mathrm{e}}=$ equilibrium liquid phase adsorbate concentration at solid-liquid interface $\left(\mathrm{ML}^{-3}\right)$

$\mathrm{C}_{0}=$ initial liquid phase concentration $\left(\mathrm{ML}^{-3}\right)$

$\mathrm{C}_{\mathrm{s}}=$ liquid phase adsorbate concentration at solid-liquid interface $\left(\mathrm{ML}^{-3}\right)$

$\mathrm{C}_{\mathrm{t}}=$ bulk liquid phase adsorbate concentration $\left(\mathrm{ML}^{-3}\right)$

$\mathrm{d}_{\mathrm{p}}=$ adsorbate particle diameter $(\mathrm{L})$

$\mathrm{D}_{\mathrm{s}}=$ surface diffusion coefficient $\left(\mathrm{L}^{2} \mathrm{~T}\right)$

$\mathrm{K}=$ Frendlich isotherm capacity constant, dimensions vary with $\mathrm{n}$

$\mathrm{K}_{\mathrm{f}}=$ liquid film mass transfer coefficient $\left(\mathrm{LT}^{-1}\right)$

$\mathrm{M}=$ total mass of carbon in closed batch test $(\mathrm{M})$

$\mathrm{n}=$ Freundlich isotherm intensity constant (dimensioness)

$\mathrm{q}(\mathrm{r}, \mathrm{t})=$ adsorbed phase adsorbate concentration $\left(\mathrm{MM}^{-1}\right)$

$\mathrm{q}_{\mathrm{e}}=$ equilibrium average adsorbed phase adsorbate concentration $\left(\mathrm{MM}^{-1}\right)$

$\mathrm{q}_{0}=$ reference adsorbed phase adsorbate concentration corresponding to the initial liquid phase concentration $\left(\mathrm{MM}^{-1}\right)$

$\mathrm{q}_{\text {avg }}=$ average adsorbed phase adsorbate concentration $\left(\mathrm{MM}^{-1}\right)$

$\mathrm{q}_{\mathrm{s}}(\mathrm{t})=$ adsorbed phase adsorbate concentration at solid-liquid interface $\left(\mathrm{MM}^{-1}\right)$

$\rho_{\mathrm{p}}=$ apparent particle density $\left(\mathrm{ML}^{-1}\right)$

$\mathrm{r}=$ radial coordinate radial coordinate

$\mathrm{t}=$ time $(\mathrm{T})$

$\mathrm{V}=$ liquid volume in close batch test $\left(\mathrm{L}^{3}\right)$

\section{Acknowledgment}

Funding for this research was provided by the Queensland Government (Australia) and the Australian Research Council.

\section{References}

Best, G., Mourato, D., Singh, M., Firman, M., and Basu, S. (1999). "Application of immersed ultrafiltration membranes for colour \& TOC removal." Membrane technol., 112, 5-12.

Campos, C., Mariñas, B. J., Snoeyink, V. L., Baudin, I., and Lainé J. M. (2000a). "PAC-membrane filtration process. I Model Development." J. Envir. Engrg., ASCE, 126 (2), $97-103$.

Campos, C., Mariñas, B. J., Snoeyink, V. L., Baudin, I., and Lainé J. M. (2000b). "PAC-membrane filtration process. II: Model Application.” J. Envir. Engrg., ASCE, 126 (2), $104-111$

Campos, C., Mariñas, B. J., Snoeyink, V. L., Baudin, I., and Lainé J. M. (1998). "Adsorption of trace organic (D)

P. (1996). "Coagulation: its effect on organic matter." J. . A

Sci. Total Environ., 225, 109-18. works." Environ Sci Technol, 35 (24), 4697-2703.

Knappe, D. R. U., Matsui, Y., Snoeyink, V. L., Roche, P., Prados, M. J., and Bourbigot, M. M. (1998). "Predicting the capacity of powdered activated carbon for trace organic compounds in natural waters." Environ. Sci. Technol., 32, $1694-98$.

Körner, W., Bolz, U., Süssmuth, W., Hiller, G., Schuller, W., Hanf, V., and Hagenmaier, H. (2000). “Input/output balance of estrogenic active compounds in a major municipal sewage plant in Germany." Chemosphere, 40, 1131

Lai, K. M., Johnson, K. L., Scrimshaw, M. D., and Lester, J. N. (2000). "Binding of waterbome steroid estrogens to

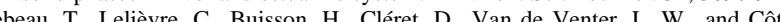

Côté, P. (1998). "Immersed membrane for NOM and SOCs removal." Desalination, filtration for the

Lee, H. W., Kim, K. J., and Fane, A. G. (1997). "Removal of phenol by adsorption on powdered activated carbon in a continuous flow stirred cell membrane system." Sep. Sci. Technol., 32 (11), 1835 - 1849.

Morris, J. C., and Weber, W. J. Jr. (1964). "Adsorption of biochemically resistant materials from solution, Part I." U. S Public Health Service, AWTR-9 Rept. 999-WP-11.

Morris, J. C., and Weber, W. J. Jr. "Adsorption of biochemically resistant materials from solution, Part II.” U. S. Public Health Service, AWTR-16 Rept. 999-WP-33.

Najm, I. N., (1996). "Mathematical modeling of PAC adsorption processes." J. AWWA, 88(10), 79-89.

Pirbazari, M., Badriyha, B. N., and Revindran, V. (1992) "MF-PAC for treating waters contaminated with natural and (1979). "Rent.

. on soluble secondary-effluent organics." J. Environ. Eng. Div.

Roy, D., Wang G. T and Adrian, D. D. (1993). "A simplified solution technique for carbon adsorption model," War. Res., 27 (6), 1033-1040.

Sumpter, J. P., and Jobling, S. (1995). "Vitellogenesis as a biomarker for estrogenic contamination of the aquatic environment." Environ. Health Perspect., 103, 173 - 8.

Suzuki, T., Watanabe, Y., Ozawa, G., and Ikeda S. (1998). "Removal of soluble organics and manganese by a hybrid MF hollow fibre membrane system." Desalination, 117, $119-130$

Traegner, U. K., and Suidan, M. T. (1989). "Evaluation of surface and film diffusion coefficients for carbon adsorption. Wat. Res., $23,267-273$

Ternes, T. A., Stumpf, M., Mueller, J., Haberer, K., Wilken, R. D, and Servos, M. (1999). "Behavior and occurrence of estrogens in municipal sewage treatment plants - I. Investigations in Germany, Canada and Brazil." Sci. Total

Chakravorty, R. K. (1974). "Pore and solid diffusion models for fixed bed adsorbers.” AIChE. J., 20, 228-238. 
Chang, S. ; Waite, T.D. ; Ong, P.E.A. ; Schäfer, A.I. ; Fane, A.G. (2004)

Assessment of Trace Estrogenic Contaminants Removal by Coagulant Addition, Powdered Activated Carbon Adsorption and Powdered Activated Carbon/Microfiltration Processes, ASCE Journal of Environmental Engineering, 130, 7, 736-742.

Table 1. Equations for the homogenous diffusion model (after Roy et al. 1993)

\begin{tabular}{|c|c|c|}
\hline $\begin{array}{l}\text { Equation } \\
\text { No. }\end{array}$ & Equation & Role \\
\hline 2 & $\frac{d C_{b}}{d t}=-M \frac{d q_{\text {avg }}}{d t}$ & Mass balance for closed batch test \\
\hline 3 & $q_{\text {avg }}=\frac{3}{\left(d_{p} / 2\right)^{3}} \int_{0}^{d_{p} / 2} q(r, t) r^{2} d r$ & Average carbon \\
\hline 4 & $\frac{\partial q}{\partial t}=\frac{D_{s}}{r^{2}} \frac{\partial}{\partial r}\left(r^{2} \frac{\partial q}{\partial r}\right)$ & $\begin{array}{l}\text { Diffusion equation for a spherical } \\
\text { particle }\end{array}$ \\
\hline 5 & $q(r, 0)=0$ & Initial condition \\
\hline 6 & $\frac{\partial q}{\partial r}=0 \quad$ for $\mathrm{r}=0$ & Boundary condition for contin \\
\hline 7 & $\rho_{p} D_{s} \frac{\partial q}{\partial r}=K_{f}\left(C_{t}-C_{s}\right)$ & $\begin{array}{l}\text { Boundary condition for continuity } \\
\text { of flux at } r=d_{p} / 2\end{array}$ \\
\hline 8 & $q_{s}=K C_{s}^{n}$ & $\begin{array}{l}\text { Freundlich isotherm for } \\
\text { equilibrium at solid-liquid } \\
\text { interface }\end{array}$ \\
\hline
\end{tabular}

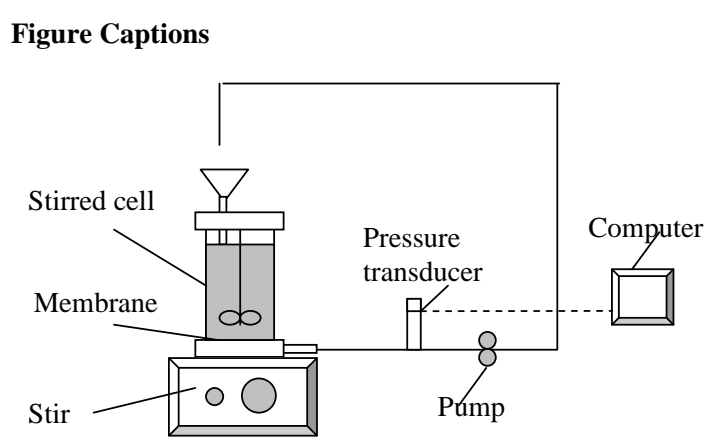

Figure 1. Schematics of the stirred cell system used.

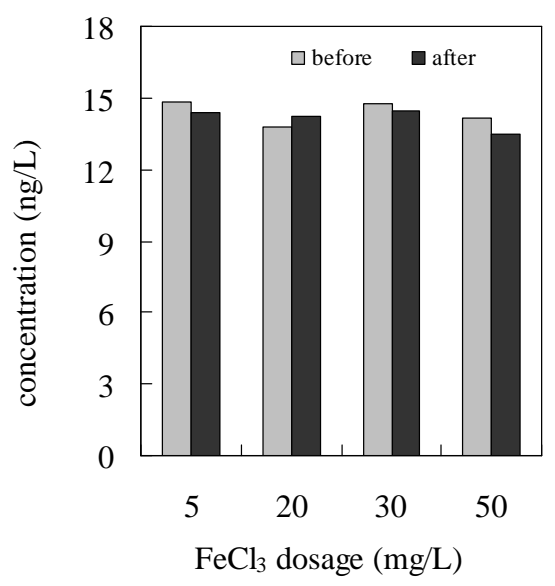

Figure 2 a. Estrone concentrations before and after addition of different doses of ferric chloride $(\mathrm{pH}=7.49)$ 
Chang, S. ; Waite, T.D. ; Ong, P.E.A. ; Schäfer, A.I. ; Fane, A.G. (2004)

Assessment of Trace Estrogenic Contaminants Removal by Coagulant Addition, Powdered Activated Carbon Adsorption and Powdered Activated Carbon/Microfiltration Processes,

ASCE Journal of Environmental Engineering, 130, 7, 736-742.

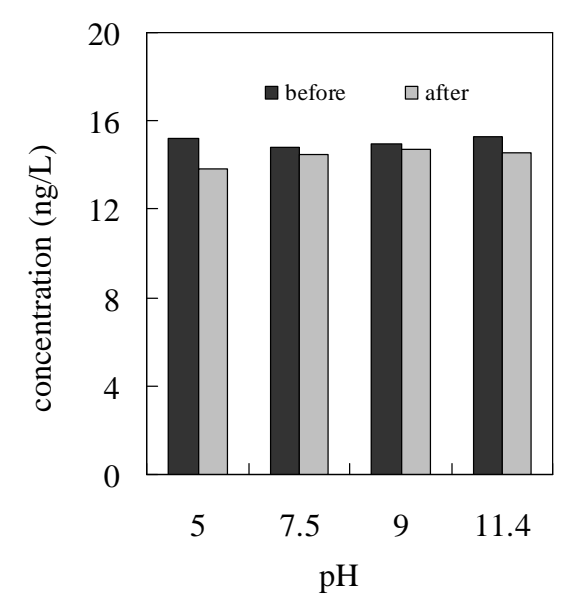

Figure $2 \mathrm{~b}$ Estrone concentrations before and after addition of hydrolysable metal salt for different initial $\mathrm{pH}$ conditions (dosage: $30 \mathrm{mg} / \mathrm{L}$ )

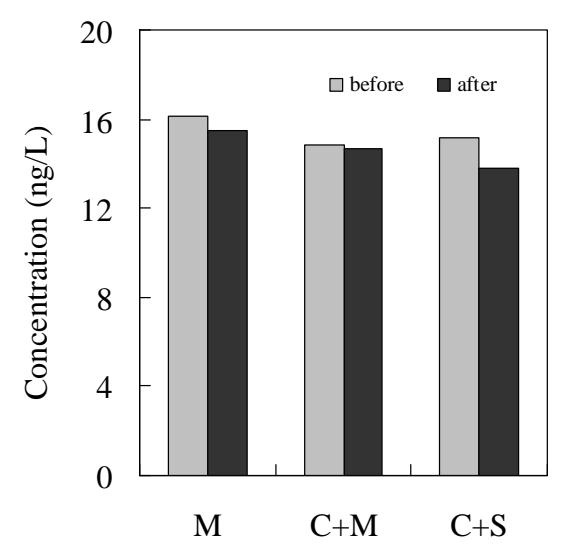

Figure 3 Estrone concentrations after being treated by different processes. (M: membrane filtration; $\mathrm{M}+\mathrm{C}$ : membrane filtration +coagulation; $\mathrm{C}+\mathrm{S}$ : coagulation +settling)

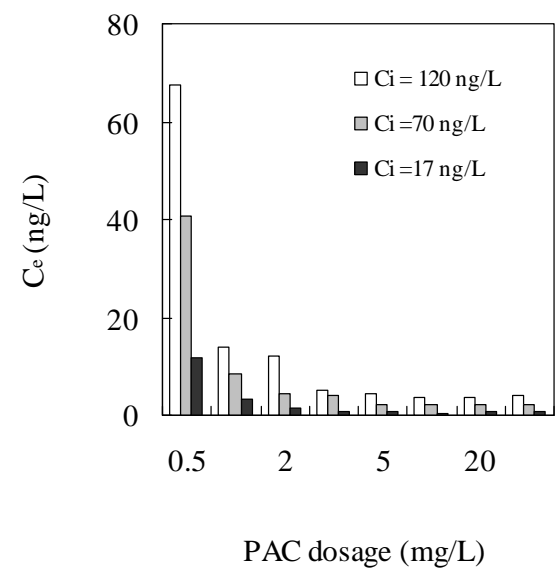

Figure 4.Final (equilibrium) estrone concentrations obtained following addition of a range of doses of powdered activated carbon (PAC) for initial estrone concentrations of 17, 70 and 120 $\mathrm{ng} / \mathrm{L}$.

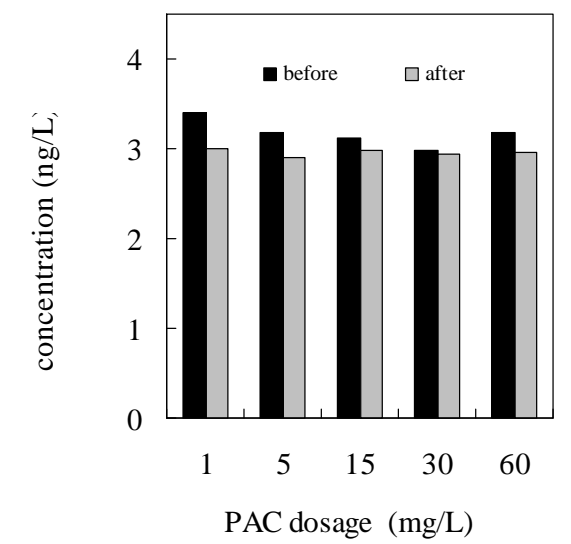

Figure 5. Initial and final estrone concentration following a second addition of PAC (in carbonate buffer solution). 
Chang, S. ; Waite, T.D. ; Ong, P.E.A. ; Schäfer, A.I. ; Fane, A.G. (2004)

Assessment of Trace Estrogenic Contaminants Removal by Coagulant Addition, Powdered Activated Carbon Adsorption and Powdered Activated Carbon/Microfiltration Processes,

ASCE Journal of Environmental Engineering, 130, 7, 736-742.

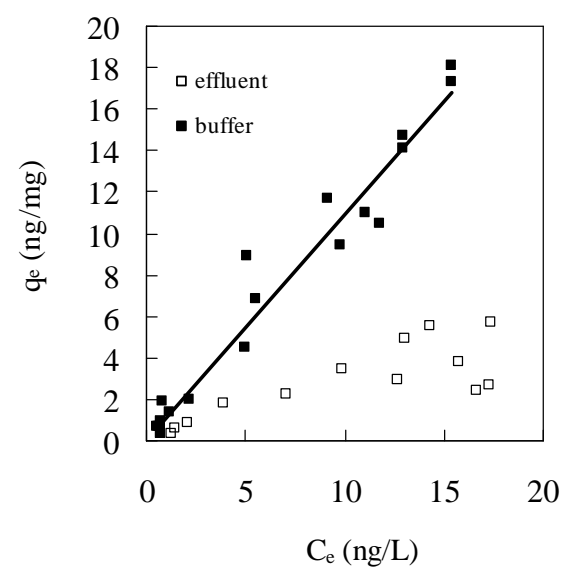

Figure 6. Isotherm equilibrium relationships for estrone adsorption on PAC in carbonate buffer solution and secondary effluent.

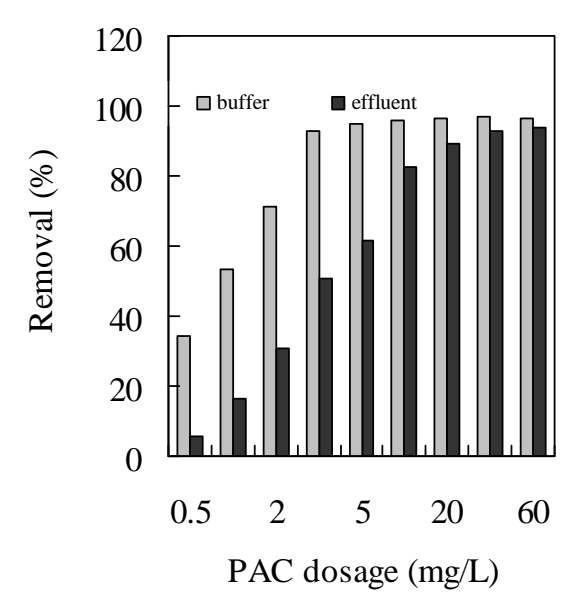

Figure 7. Comparison of the percentage removal of estrone from carbonate buffer and secondary effluent for different doses of PAC.

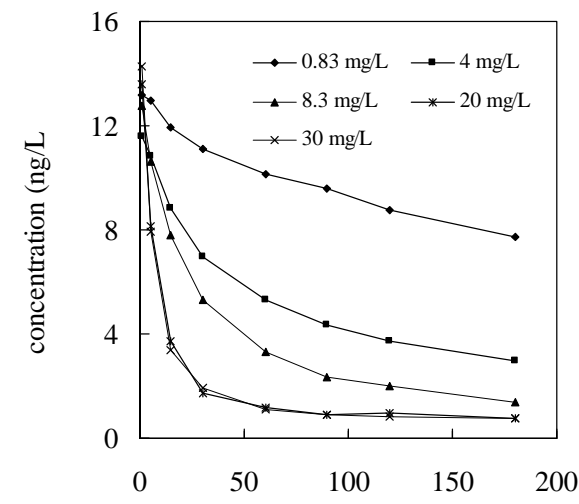

time (min)

Figure 8. Change in estrone concentration in permeate following addition of different doses of PAC into the stirred cell.

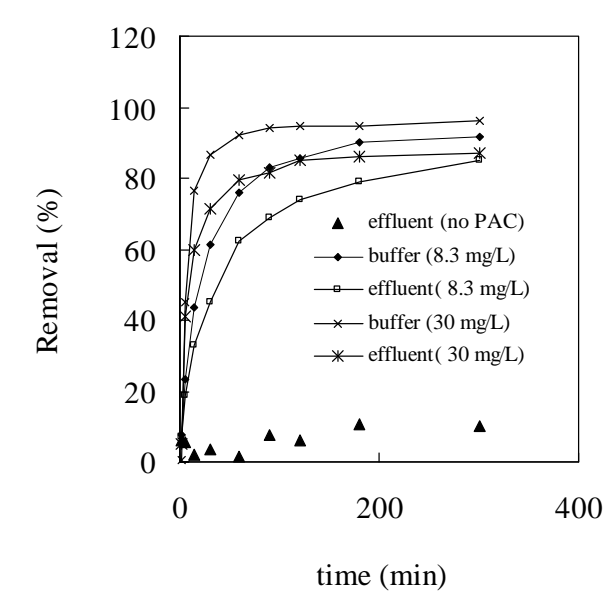

Figure 9. Estrone removal from the secondary effluent and carbonate buffer solution in the absence and presence of different doses of PAC. 
Chang, S. ; Waite, T.D. ; Ong, P.E.A. ; Schäfer, A.I. ; Fane, A.G. (2004)

Assessment of Trace Estrogenic Contaminants Removal by Coagulant Addition, Powdered Activated Carbon Adsorption and Powdered Activated Carbon/Microfiltration Processes,

ASCE Journal of Environmental Engineering, 130, 7, 736-742.

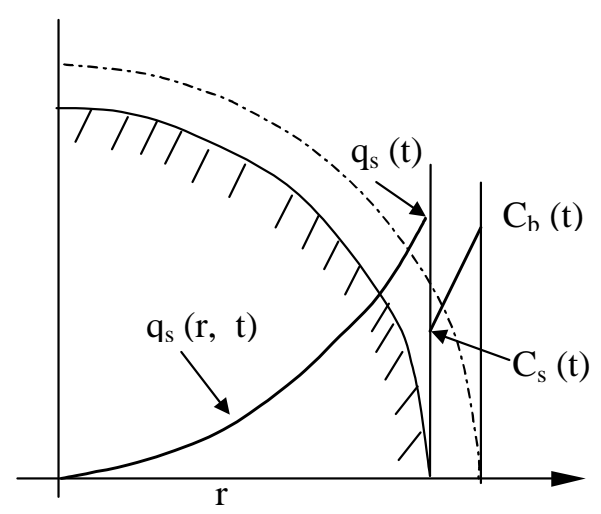

Figure 10. Schematic of mass transfer processes operating in activated carbon adsorption.

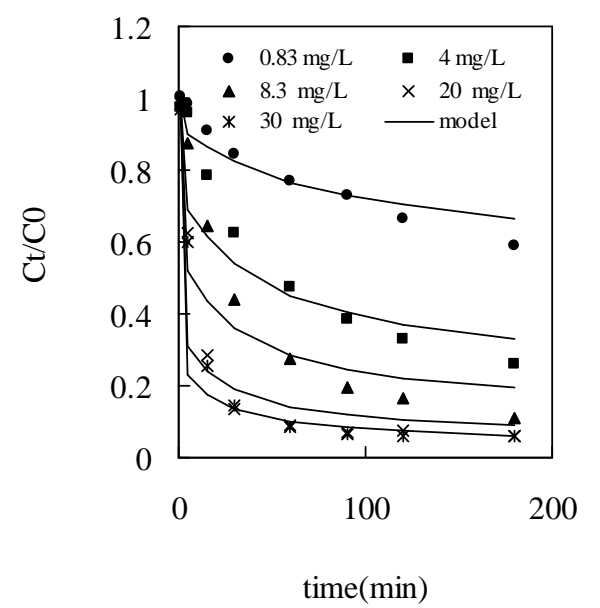

Figure 11 a. Experimental and simulated $\mathrm{C}_{\mathrm{t}} / \mathrm{C}_{0}$-t relationships (no-film diffusion limitation model).

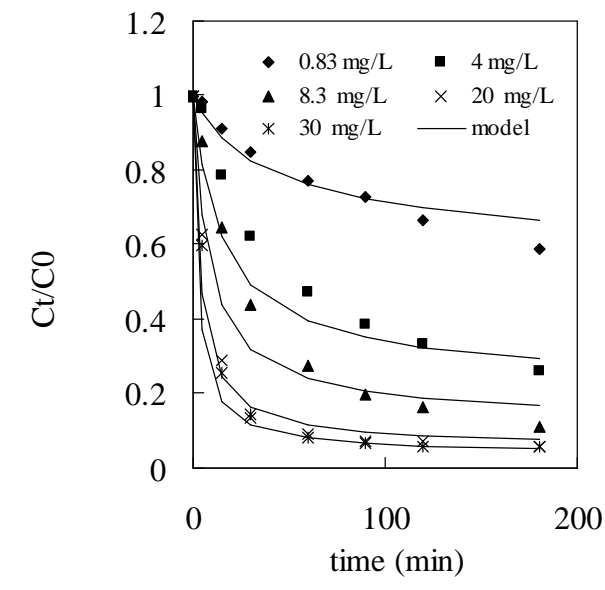

Figure $11 \mathrm{~b}$. Experimental and simulated $\mathrm{C}_{\mathrm{t}} / \mathrm{C}_{0^{-}}$-t relationships (film and surface diffusion limitation model).

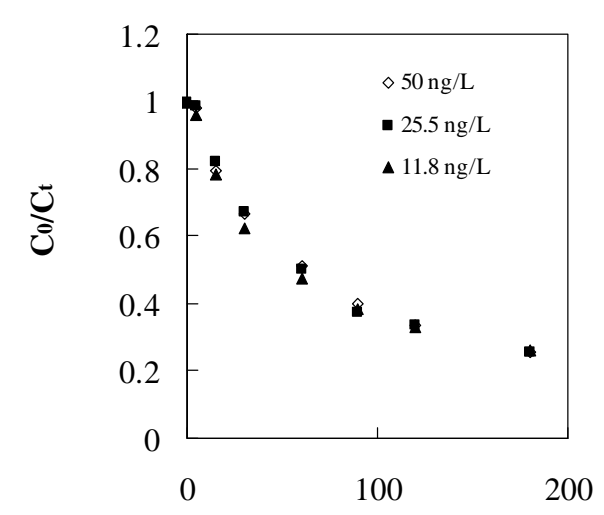

time (min)

Figure 12. Experimental $\mathrm{C}_{\mathrm{t}} / \mathrm{C}_{0}$-t relationships for different initial estrone concentrations. 